\title{
Vulgarly Called The Throat-Distemper: New Jersey's Two-Century Struggle Against Diphtheria
}

\section{By Sandra W. Moss}

\section{DOI: $\underline{\text { https://doi.org/10.14713/njis.v6i2.213 }}$}

In 1740, minister and physician Jonathan Dickinson of Elizabethtown, New Jersey, published "Observations on that Terrible Disease Vulgarly Called the Throat-Distemper," a short treatise on the diagnosis and treatment of epidemic diphtheria for the benefit of physicians in Boston. Dickinson's pamphlet was a landmark in American colonial medical literature. It was New Jersey's first-and last-important original contribution to the medical literature on diphtheria. For the next two centuries, New Jersey, with no medical colleges or prestigious teaching hospitals of its own, would import the medical knowledge and innovations necessary to control and finally eradicate the disease that cruelly killed thousands of New Jersey children in the two centuries following Dickinson's report. This article examines the processes by which New Jersey practitioners and public health officers imported, processed, disseminated, and applied the lessons of the germ theory and immunology in their two-century quest to banish one of the great scourges of childhood.

\section{"The Most Horrible Scourge of Them All"}

Aretaeus the Greek observed "ulceration about the tonsils." John Huxham of Devon described "malignant ulcerous sore throat." Francis Home of Edinburgh invoked the Latin "angina maligna." Samuel Bard, professor at New York's King's College, wrote his 1771 treatise on "angina suffocativa." In Spain, the epidemic year 1613 became known as "el año de los garrotillos"- the year of strangulations. ${ }^{1}$ Well into the nineteenth century, New Jersey medical

\footnotetext{
${ }^{1}$ Ralph H. Major, Classic Descriptions of Disease, 3rd ed. (Springfield, IL: Charles C. Thomas, 1945), 136-37, 14957. Angina is a general term for a localized pain.
} 
men used the term "membranous croup." Across continents and centuries, the majority of victims of this malady were young children.

In 1826, French physician Pierre Bretonneau named the disease diphthérite-from the Greek for "leather" or "hide" — referring to the thick rubbery coating that lined the tissues of the upper airway. ${ }^{2}$ Since the coating was comprised of the debris of damaged cells rather than live membranous tissue, it was correctly referred to as a "pseudomembrane." The pseudomembrane, particularly when it extended to the larynx (voice box), caused progressive airway obstruction and, in many cases, an anguishing death. In some children, a circulating bacterial toxin attacked the heart and nervous system late in the illness, causing further morbidity and mortality.

New Jersey historian of medicine David Cowen commented on the ravages of infectious diseases among children: "The most horrible scourge of them all was diphtheria. There was something about this sickness more detestable and insidious than any of the others: its devious way of spreading, its unpleasant manifestations, its slaughter of mothers and children, its danger to doctors and nurses, and its invincibility."3

\section{The 1735 Epidemic "Vulgarly Called the Throat-Distemper"}

Ministers in the American colonies, as the best-educated men in early settlements, were often consulted for medical advice. Boston's Puritan minister Cotton Mather, who referred to medicine and religion as the "angelic conjunction," recorded the 1659 "Malady of Bladders in the Windpipe - that invaded and removed many Children." 4 A devastating diphtheria epidemic, first reported in New Hampshire, descended on the northern colonies in the mid-1730s. Noah Webster

\footnotetext{
${ }^{2}$ Pierre Bretonneau, Des inflammations spéciales du tissu muqueux, et en particular de la diphthérite, ou inflammation pelliculaire (Paris: Chez Crevot, 1836); excerpt in Major, Classic Descriptions, 159-61.

${ }^{3}$ David L. Cowen, The New Jersey Historical Series: Medicine and Health in New Jersey (Princeton: D. Van Nostrand, 1964), 43.

${ }^{4}$ Cotton Mather, Magnalia Christi Americana: The Ecclesiastical History of New England from Its First Planting in 1620, until the Year of Our Lord 1698 (London: Thomas Parkhurst, 1702), IV:156.
} 
observed, "It was literally the plague among children. Many families lost three of four childrenmany lost all.",5

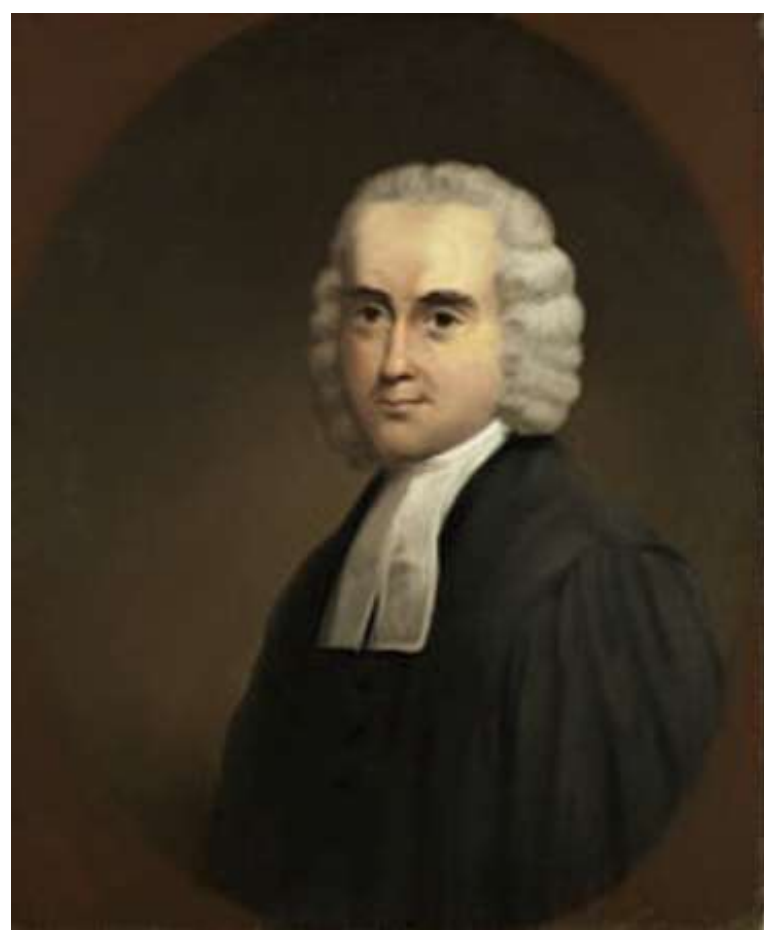

Reverend Jonathan Dickinson (1688-1747), first president of the College of New Jersey. Painting by Edward Ludlow Mooney, Nassau Hall, Princeton University, courtesy Princeton University Art Museum, with permission.
In New Jersey, Reverend Jonathan Dickinson (1688-1747) of Elizabethtown (Elizabeth) served the Presbyterian Church from 1709 , "ministering to his flock as pastor, lawyer, physician, and in later years, as an instructor of young men preparing for professional study." "The "throat-distemper" struck Elizabethtown and the surrounding area in February $1735 .^{7}$ In 1740 , Dickinson recorded his medical observations in the form of an eleven-page letter of advice to Boston medical men. Dickinson's Observations On That Terrible Disease Vulgarly Called The ThroatDistemper With Advices As To The Method Of

Cure was "probably the first professional medical work by a Jerseyman." 8

Dickinson wrote of "the surprising mortality of this distemper," the "awful desolations," and the "first assault" in a "distressed family" that proved fatal in eight of its ten children within a fortnight. In one of these children "newly dead," he conducted a dissection (autopsy), to gain a

\footnotetext{
${ }^{5}$ Noah Webster, A Brief History of Epidemic and Pestilential Diseases; with the Principal Phenomena of the Physical World, which Precede and Accompany Them, and Observations Deduced from the Facts Stated (Hartford: Hudson \& Goodwin, 1799), I:233.

${ }^{6}$ For a few months before his death in 1747, Dickinson was named the first president of the College of New Jersey (later Princeton), instructing students in the rectory in Elizabeth. Princeton University, "Presidents of Princeton University," https://pr.princeton.edu/pub/presidents/dickinson/index.html (accessed January 12, 2020).

${ }^{7}$ By the Julian calendar, then in use, the new calendar year was March 25. In the style of the day, Dickinson wrote "February 1734.5" when referring to the outbreak.

${ }^{8}$ Cowen, Medicine and Health in New Jersey, 21.
} 
"better acquaintance with the nature of the disease." Dickinson was a keen observer and described a range of clinical manifestations. In the most serious cases, "the disease progressed rapidly with death within twenty-four hours but thro' the divine Goodness, these symptoms have been more rarely seen among us, and there have been but few in this manner snatch'd out of the World." 9

Early sore throat was often followed by "tumefaction [swelling] of the tonsils, uvula, and epiglottis, and sometimes of the jaws, and even of the whole throat and neck... the tonsils first and in a little time the whole throat covered with a whitish crustula." If this "crustula" (i.e., the pseudomembrane) invaded the larynx, "the poor miserable creature struggles, until released by a perfect suffocation, or stoppage of the breath." 10

Dickinson's observations on the early cases led him to "methods of cure." Remedies for various clinical manifestations reflected the pharmaceutical practices of the day. In addition to harsh calomel (mercurial chloride) purges, treatments for a range of symptoms included Virginia snakeroot, laudanum (opium in wine), treacle, saffron, emetics (often ipecac), fomentations (poultices), and steams made with medicinal plants. With the exception of laudanum, which may have relieved suffering, and perhaps the use of steam, all are now known to be either toxic or useless. Dickinson ended his treatise with a note to his fellow medical men: "If this proves of any service, I shall have cause of Thankfulness. If not, you'll kindly accept my willingness to serve you, and to contribute what I can towards the relief of the afflicted and miserable."11

\footnotetext{
${ }^{9}$ Jonathan Dickinson, Observations On That Terrible Disease Vulgarly Called The Throat-Distemper. With Advices As To The Method Of Cure. In A Letter To A Friend (Boston: S. Kneeland and T. Green, 1740): 1-11 passim.

${ }^{10}$ Ibid., 4.

${ }^{11}$ Ibid., 6.
} 


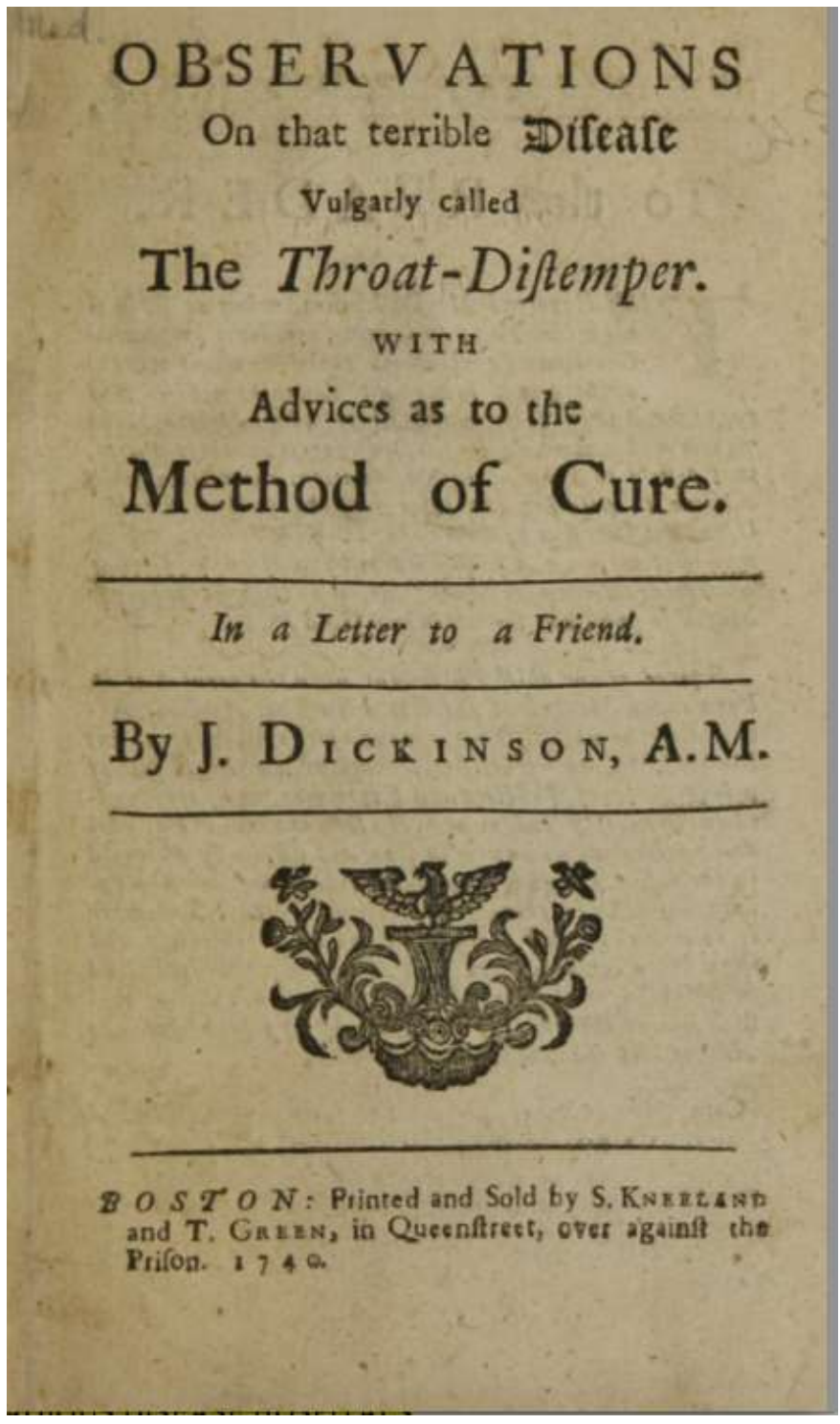

Cover page of Rev. John Dickinson's treatise on the "throat distemper," 1740. Images in the History of Medicine, National Library of Medicine.

Although there was no central reporting mechanism, other towns in New Jersey were similarly affected. John Peter Zenger's New York Weekly Journal reported in the February 9, 1736 edition: "We are inform'd, that at Corswicks [sic; Crosswicks] in West New-Jersey divers Persons have died lately of a Distemper in the Throat and that that Distemper prevails there." On February 16, Zenger inserted a letter sent to the Weekly Journal by Dickinson "containing an Account [of 
the Elizabeth area epidemic] and proposing a Method [of cure]." Zenger published Dickinson's letter again the following week, thinking it "might be of service." 12

\section{Speculative Theories about the Cause of Diphtheria}

Confusion and uncertainty about the cause of diphtheria hampered any progress toward rational treatment or prevention. Therapy had changed little in the century after Dickinson published his essay on the "throat distemper" in 1740.

In the 1840s, Dr. Joseph Parrish of Burlington reasoned that the "pseudomembranous or laryngeal croup... originated in a peculiar condition of the blood, the tendency of which is to form adventitious membrane," thus prompting treatments that altered "the vital fluid" (blood): alkaline remedies, emetics, purgatives, leeches to the throat, and cataplasms (poultices) to the chest and feet, along with local application of silver nitrate "by means of a camel's hair pencil" to the membrane covering the throat. ${ }^{13}$

For another forty years, physicians could only speculate about the cause of the disease. In his 1880 report to the Board of Health, Dr. Ezra Mundy Hunt, New Jersey's pioneering sanitarian and public health leader, favored an etiologic role for "filth incident to human habitations," although it is "sometimes derived from persons, or conveyed by things, and thus communicable."14 Dr. Frank Wilmarth of Essex County observed that diphtheria cases in Orange and its vicinity "hovered about low, poorly drained localities almost entirely, leaving but little doubt that its origin holds a close relationship with unfavorable sanitary surroundings." 15

\footnotetext{
12 William A. Whitehead (ed.), Documents Relating to the Colonial History of the State of New Jersey, 1704-1793 (Paterson: Press Printing and Publishing Co., 1894), 11:443-44.

13 "Abstract of the Proceedings of the District Medical Society for the County of Burlington," New Jersey Medical Reporter and Transactions of the Medical Society of New Jersey 1 (1847-1848): 102-104.

${ }^{14}$ Ezra M. Hunt, "Report of the Secretary of the Board," Fourth Annual Report of the Board of Health of the State of New Jersey (1880): 12.

${ }^{15}$ Frank Wilmarth, "Reports of District Societies: Essex County," Transactions of the Medical Society of New Jersey (1875): 138-39; quotation, 139.
} 
Such speculations suggested no clear path forward. The "plague among children" 16 continued unabated through much of the nineteenth century. In the small town of Bass River (Burlington County), for example, the winter and spring of 1875-76 saw a "fearful scourge of diphtheria" with an estimated 150 cases and 10 percent mortality according to the local physician. ${ }^{17}$

\section{The Therapeutic Landscape}

Diphtheria's therapeutic landscape was contentious, chaotic, largely anecdotal, and little changed in the century and more since Dickinson's essay on the "Throat Distemper." In the shortlived New Jersey Medical Reporter, the editor, Dr. Joseph Parrish of Burlington, remarked in 1849, "Among the diseases of childhood, there is probably none which has excited more attention and solicitude than that usually known as membranous croup." The usual aggressive treatmentbloodletting, purging, vomiting, blistering — had not "proved equal to the insidious enemy against which it has been arrayed." Parrish advised "remedies more mild and palliative...as the result cannot be worse." His regimen, though less harsh, included the usual emetics, purgatives, and applications of silver nitrate to the membrane. ${ }^{18}$

In Somerset County Dr. Henry VanDerveer found no value in stripping the pseudomembrane from the back of the throat with forceps or in topical medicinal applications to the membrane. He recommended treatment with an "active cathartic and antimony or ipecac in diaphoretic doses or combined with chlorate or bicarbonate of potassa." Evidently, some doctors believed that violent vomiting induced by ipecac might shake loose the membrane that coated the throat.

\footnotetext{
${ }^{16}$ Webster, Brief History of Epidemic and Pestilential Diseases, I:233.

17 Theophilus Price, "Report from Burlington County," Transactions of the Medical Society of New Jersey (1876): 185.

${ }^{18}$ Joseph Parrish, "Remarks on the Treatment of Pseudo-membranous Laryngitis," New Jersey Medical Reporter and Transactions of the Medical Society of New Jersey 2 (1849): 59-63; quotations, 59, 60.
} 
In severe cases with swelling, VanDerveer advised application of leeches externally over the front of the neck to draw the blood toward the surface of the skin and, according to current medical theory, to reduce the swelling inside the throat. Similarly, application of liniment over the front of the neck might reduce internal inflammation by the process of "counterirritation." On a professional note, VanDerveer observed that a recent "attack has been sufficiently severe to excite alarm in the community and cause solicitude to the [mainstream medical] profession."19

In 1878, Dr. William Gray of East Orange looked back in despair-and some anger-at past therapies:

The subduing of the inflammation has been the study of the past; hence we find that all the antiphlogistics [anti-inflammatory drugs] of the materia medica [all available pharmaceuticals] have been in vogue: now bloodletting, now leeches, now antimony, now calomel, and so on through the list, until between the treatment and disease, but little chance was left for the patient. How a child of such tender years, as these patients generally are, could possibly live through such treatment as we find laid down in the books, passes our comprehension; to say nothing of the great loss of vitality by the other treatments recommended, the emesis advocated is enough to kill any child...

Yet, Gray confessed, the therapies available in the 1870s left physicians "as helpless as all who have preceded us, no medical weapon having yet been forged capable of penetrating its armor." His own efforts were directed toward "the arrest of the exudation" (the diphtheric pseudomembrane that obstructed the throat). The goal was to decrease the flow of blood to the "inflamed part," thus decreasing the inflammation and the subsequent membrane formation. Emetics to induce vomiting and thereby help detach the membrane, caustic applications to the throat directly to the membrane, and antiphlogistic (anti-inflammatory) treatments were useless and could only add to the child's misery. Gray instead favored atropine, a drug known to dry respiratory secretions, with the addition of digitalis, ergot, quinine, and cold compresses to the

\footnotetext{
${ }^{19}$ H.F. VanDerveer, "Report of District Societies: Somerset County," Transactions of the Medical Society of New Jersey (1866): 282-86; quotations, 283, 285.
} 
throat to reverse the known toxic side effects of atropine. ${ }^{20}$ Though in retrospect Gray's regimen was similarly useless, he was thoughtfully applying the best pharmacological principles of his day.

Lest we be too critical, it is well to reflect that during diphtheria epidemics, these men saw the daily suffering and death of children on a scale that is difficult for us to imagine. Many of them practiced in isolation. Though their own medical education was sometimes limited, their therapies were not unlike those of the leading medical authorities of the day. They were not called to the bedside of a suffering child to do nothing. In the face of death and a terrified family, they felt compelled to do everything they could.

Occasional reports of happy outcomes provided some encouragement. In 1854, Dr. Zachariah Read of Mount Holly attended a toddler near death; the family refused tracheotomy, “choosing rather to let him die." In desperation, Read introduced a probang (flexible wand) soaked in silver nitrate deep into the throat to attack the membrane. Breathing quickly improved and by the next day he was the "most lively of a group of six children." 21

\section{Tracheostomy and O'Dwyer Tubes}

In the 1830 s, in an effort to maintain an open airway until the throat inflammation and obstructing membrane resolved, Armand Trousseau in Paris performed surgical tracheostomies in scores of "croup" patients with some success. While tracheostomy, in which a tube is placed in the lower airway through a surgical incision in the neck, had a long and uneven history, non-surgical intubation of the trachea was a novel mid-nineteenth-century approach to maintaining the fragile airway in an asphyxiating child. In the late 1850s, Eugène Bouchut, a Parisian pediatrician,

\footnotetext{
${ }^{20}$ William K. Gray, "Membranous Croup and Laryngeal Catarrh," Transactions of the Medical Society of New Jersey (1878): 377-83; quotations, 378.

${ }^{21}$ Zachariah Read, "On the Topical Application of Nitrate of Silver, by Means of the Probang in Membranous Croup," New Jersey Medical Reporter and Transactions of the Medical Society of New Jersey (1854): 428-29; quotations, $428,429$.
} 
successfully introduced a curved catheter with a small straight metal tube through the mouth, into the throat, and past the membranous obstruction. The procedure was painful and traumatic to the mucosa, and rejected by French medical authorities.

In the mid-1880s, pediatrician Joseph O'Dwyer at the New York Foundling Hospital independently reinvented, refined, and improved Bouchut's instruments and methods. O'Dwyer's technique and O'Dwyer tubes were rapidly and enthusiastically adopted in the United States and, with some hesitation, in Europe. ${ }^{22}$ In 1891, Dr. Walter Johnson, surgeon to the Paterson Eye and Ear Infirmary, citing the work of O'Dwyer, reported eighteen cases of laryngeal intubation for diphtheria. Johnson provided detailed illustrations with images of tubes of varying diameters and the instruments required to carry out the intubation. He advised physicians to practice on cadavers. Although only three of his cases survived, "in nearly every case the tube was a source of relief and comfort by preventing asphyxia." 23

Among Essex County's best prepared physicians were German immigrants escaping the 1848-49 revolutions in Europe. The German community founded Newark German Hospital in late 1870. In the hospital's first twenty years, "physicians of this neighborhood" performed tracheotomies on 110 children, of whom only thirteen - all in the previous five years prior to 1886-recovered. Dr. Robert Staehlin of Newark detailed these thirteen "hopelessly lost" survivors of diphtheritic croup. Staehlin and his colleagues concluded that a child facing death

\footnotetext{
${ }^{22}$ G. Sperati and D. Felisati, "Bouchut, O’Dwyer and Laryngeal Intubation in Patients with Croup," Acta Otorhinolaryngologica Italica 27 (December 2007): 320-23; Anne Hardy, "Tracheotomy versus Intubation: Surgical Intervention in Diphtheria in Europe and the United States, 1825-1930," Bulletin of the History of Medicine 66 (1992): 536-59.

${ }^{23}$ Walter Johnson, "Intubation of the Larynx, with a Report of Eighteen Cases," Transactions of the Medical Society of New Jersey (1891): 157-94; quotation, 189.
} 
from suffocation "should always be given the chance, slim though it may be, of tracheotomy." While operating too early presents an unnecessary risk, operating too late was the greater error. ${ }^{24}$ Dr. Edgar Holden of Newark, an innovative and well-prepared physician with multiple publications in national medical journals, transcended New Jersey's provinciality. Along with his clinical acumen in cardiovascular and pulmonary medicine, Holden specialized in laryngology, the diagnosis and treatment of diseases of the throat. In 1888, Holden addressed the annual meeting of the American Laryngological Association, beginning with a brief review of the current status of tracheotomy and O'Dwyer tubes in "croupous stenosis" (narrowing of the airway). He then displayed a divulsor (an instrument for dilating any narrow passage in the body) of his own design. The Holden divulsor featured a curved airway tube with a removable bayonet tip for piercing the cricothyroid membrane (the soft space below the thyroid cartilage, familiarly called the "Adam's

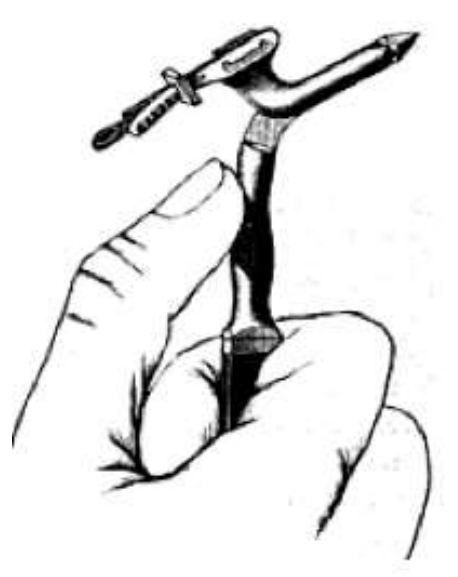

Newark physician Edgar Holden's design for his "divulsor," a proposed device for establishing an airway in cases of obstruction. Edgar Holden, "A Possible Substitute for Tracheotomy and Intubation in Certain Cases," New York Medical Journal 48 (1888): 646 - 647. apple"). Once the trachea was pierced, the sharp tip could be withdrawn and the tube left in place. The primary application was the relief of airway obstruction in diphtheria. Potential advantages included rapidity in urgent cases and little risk of serious bleeding. Holden maintained that the procedure required little special training and

\footnotetext{
${ }^{24}$ R. Staehlin, “Tracheotomy in Diphtheric Croup," Transactions of the Medical Society of New Jersey (1886): 199207; quotations: 199, 200, 203. It is assumed, but not stated, that all these tracheotomies were performed in the German Hospital. Some surgeries may have been performed in the home.
} 
could be done by a "tyro in the profession." Although colleagues urged a clinical trial of the device, there is no evidence that the Holden divulsor was ever used in practice. ${ }^{25}$

Physicians of earlier generations were well accustomed to the high toll of childhood infectious diseases. But diphtheria in particular ate at the hearts of New Jersey doctors. In 1908, Dr. George T. Welch of Passaic reflected (in somewhat inflated prose) on the ravages of diphtheria in the years before the introduction of effective therapy: "The asp that gored the bosom of Cleopatra was not so deadly... in comparison to its size, as is the bacillus diphtheria." It seemed "as if a Herod or a Moloch, stalking in darkness, should have strangled all the little children of a city...." In recalling a death from the late effects of diphtheria toxin on the heart of a child in 1890, he wrote: "Her throat was better, the membrane was disappearing, the child was begging to sit up, at which the relieved family were rejoicing. She was bolstered to a sitting posture, and asked for her doll. Suddenly the smile faded from her face, she dropped the toy, gave a little gasp, and was dead." 26

William Osler, chief of medicine at Johns Hopkins Hospital, remarked on diphtheria in his 1898 textbook, The Principles and Practice of Medicine: "No disease of temperate regions proves more fatal to physicians and nurses." ${ }^{27}$ New Jersey physicians, attending infected children and peering down inflamed throats, were not spared in the annual visitations. In 1861, Dr. Oscar Akers of Newark attended a colleague's three children, all mortally ill with diphtheria. Akers contracted the contagion and diagnosed himself: "All that his brethren could do was done to save him. He

\footnotetext{
${ }^{25}$ Edgar Holden, "A Possible Substitute for Tracheotomy and Intubation in Certain Cases," Transactions of the American Laryngological Association (1888): 30-40; republished New York Medical Journal 48 (1888): 645-48; Sandra W. Moss, Edgar Holden of Newark, New Jersey: Provincial Physician on a National Stage (XLibris, 2014), 407-10. "Tyro in the profession" was Holden's term for a novice; New York Medical Journal, 647.

${ }^{26}$ George T. Welch, "Bacteriological Notes on Diphtheria," Journal of the Medical Society of New Jersey 5 (19089): 605-9; quotations, 606, 608.

${ }^{27}$ William Osler, The Principles and Practice of Medicine, 3rd ed. (New York: D. Appleton, 1898), 189.
} 
sunk rapidly, and we [his colleagues] bore him to his grave." ${ }^{28}$ In 1903, a "brother physician" of Clayton (Gloucester County), "by devotion of duty and noble standing at his post... contracted the disease in its worst form." ${ }^{\prime 29}$ And in 1907, an epidemic of diphtheria "claimed for one of its victims a prominent physician of the town [Medford, Burlington County], after an illness of but three days." 30

\section{The Turning of the Tide}

In the closing decades of the nineteenth century, the research institutes of Europe launched a scientific assault on the epidemic diseases that stalked families and children. The New York City Health Department, with its robust facilities and well-prepared researchers, moved quickly to apply the new sciences of bacteriology and serology (immunology) to the "throat distemper."

In 1883 and 1884, German bacteriologists Edwin Klebs and Friedrich Loeffler identified the club-shaped bacterium, Corynebacterium diphtheriae (from Greek and Latin for "club") and showed that it produced a toxin. The toxin damaged the cells lining the upper airway and led to the formation of the thick gray pseudomembrane that coated the throat and potentially obstructed respiration.

In the early 1890s, Shibasaburo Kitasato and Emil von Behring, both working in Germany, found that animals injected with non-lethal doses of diphtheria toxin produced an antitoxin. In 1894, Émile Roux in Paris recorded a 50 percent reduction in mortality in hospitalized children following injection with antitoxin. Antitoxin was also effective in providing temporary immunity

\footnotetext{
${ }^{28}$ J. Henry Clark, "Oscar J. Akers," in "The First Fifty Years of the District Medical Society of Essex County," Transactions of the Medical Society of New Jersey (1867): 133-34.

${ }^{29}$ E.E. deGroft, "The Vicissitudes of a Doctor's Life," Transactions of the Medical Society of New Jersey (1903): 424-31; quotation, 429.

30 "Annual Reports of the County Society Reporters: Burlington County," Journal of the Medical Society of New Jersey 4: (1907-08): 80-81; quotation, 80.
} 
in close contacts of diphtheria victims. ${ }^{31}$

\section{The Class War on Germs}

In the 1880 s, middle and upper class families, attuned to the role of germs in disease, increasingly turned to household disinfectants to protect their children. ${ }^{32}$ The urban poor were seen as victims of their own unhygienic practices and cast as vectors of infectious disease to the better classes. The Annual Report of the Board of Health of New Jersey for 1890 observed that despite encouraging advances in bacteriology and attention to hygiene in the upper classes, some of the onus for the 1575 cases in New Jersey (1889-1890), rested on the lower classes and their unhygienic surroundings:

Diphtheria still continues to be the scourge of young life and claims as its victims many of the healthiest children and not a few of more adult age. While it is undeniable that it attains virulence and momentum from damp and filthy localities, it not infrequently leaps the boundaries of these and invades the homes where cleanliness is secured. ${ }^{33}$

Two decades later, similar sentiments about wealth, class, and germs prompted the Journal of the Medical Society of New Jersey to observe that seven cases of diphtheria occurred in schoolchildren from the "fashionable residential section" of the city. ${ }^{34}$

\section{Antitoxin from New York and Philadelphia}

The first few doses produced in horses, and administered in New York (December 1894), came from the city's private Pasteur Institute. ${ }^{35}$ In the autumn of 1894, The New York City Health Department began gearing up to produce antitoxin (spelled "antitoxine") in its own horses. The

\footnotetext{
${ }^{31}$ College of Physicians of Philadelphia, History of Vaccines Timeline, https://www.historyofvaccines.org/timeline/diphtheria (accessed March 10, 2020).

${ }_{32}$ Nancy Tomes, The Gospel of Germs: Men, Women, and the Microbe in American Life (Cambridge: Harvard University Press, 1998), 77-78.

33 "Report on Vital Statistics," Fourteenth Annual Report of the Board of Health of the State of New Jersey (1890): 318." "Comment on Some Special Diseases: Diphtheria," Fourteenth Annual Report of the Board of Health of the State of New Jersey (Trenton, 1890): 320.

34 "Public Health Items" Journal of the Medical Society of New Jersey 8 (1911-1912): 554.

35 Evelynn Maxine Hammonds, Childhood's Deadly Scourge: The Campaign to Control Diphtheria in New York City, 1880-1930 (Baltimore: Johns Hopkins University Press, 1999), 113.
} 
first two cases were treated with the health department's antitoxin in early January 1895 at New York's Willard Parker Hospital, founded in 1885 for the isolation and treatment of communicable disease cases. Production and administration of antitoxin increased rapidly. However, a sudden death in April following injection in one New York child did little to decrease the skepticism that prevailed in some medical quarters. ${ }^{36}$

Of interest to physicians in Camden County, the H.K. Mulford Company of Philadelphia established a bacteriological laboratory in 1894 and began commercial production of diphtheria antitoxin in 1895. The "medical profession" was invited to tour the laboratory and stables. Among the early users of the Mulford serum was Dr. W.S. Long of Haddonfield, who attested in July 1895 that he had used antitoxin successfully in an infant. ${ }^{37}$

\section{"Antitoxine for Newark"}

In late December 1894, a New York Times headline proclaimed: “Antitoxine [sic] for Newark." According to the brief article, the Newark Board of Health "determined to-night to establish a plant for the manufacture of antitoxin similar to the one in operation in New York." An “expert physician" from the New York laboratory would prepare the antitoxin. The program would begin with ten horses and it was expected that sale of antitoxin would make the plant selfsustaining. The article continued, "Physicians here [Newark] claim that the antitoxine purchased now at excessive prices is impure, and this has been the chief reason for the establishment of the plant." 38 It is not clear how New Jersey physicians determined that antitoxin obtained from unspecified sources was "impure." It is possible that they were observing reactions to traces of

\footnotetext{
36 “A Home Supply of Antitoxine," New York Times, January 5, 1895; Hammonds, Childhood's Deadly Scourge, 121-123.

${ }^{37}$ H.K. Mulford Company, Diphtheria Antitoxic Serum, 4th ed. (Philadelphia: H.K. Mulford Company, 1895?), 12, https://collections.nlm.nih.gov/bookviewer?PID=nlm:nlmuid-101246962-bk\#page/16/mode/1up (accessed March 10, 2020).

38 “Antitoxine for Newark," New York Times, December 21, 1894.
} 


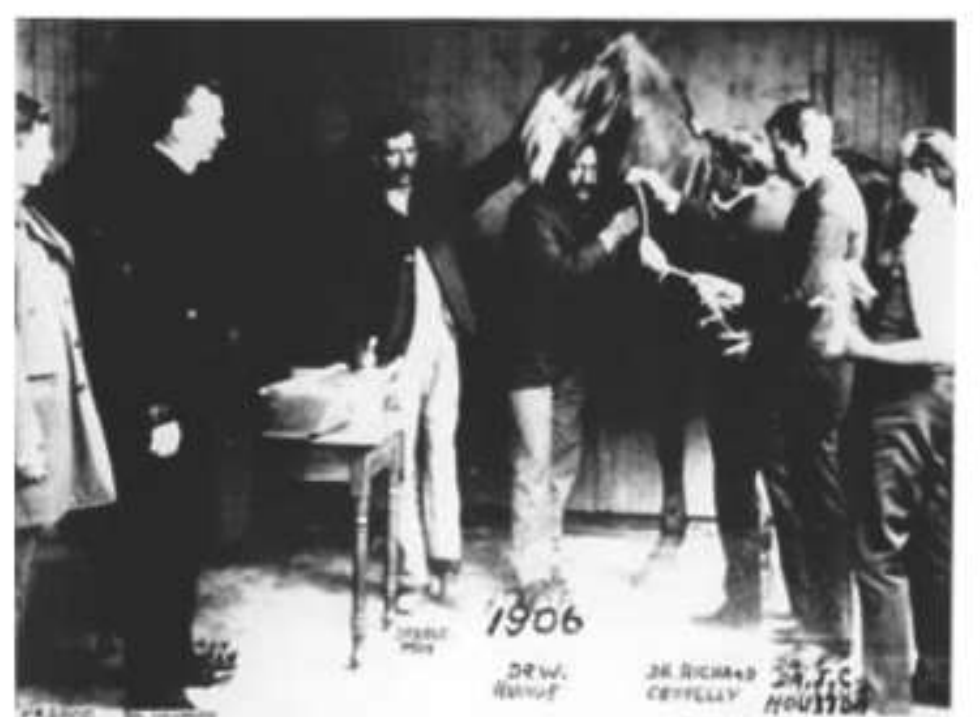

View of the Newark stable and a horse used in antitoxin production. Dr. Richard Connolly (holding the horse's rein) was bacteriologist in charge of antitoxin production. In addition to the stable man, a number of veterinarians and physicians are seen in the posed photograph. "Samuel Berg Collection, On Newark City Hospital/Martland Medical Center 1882-1963," Rutgers University Libraries, Health Sciences: History of Medicine, used with permission. horse serum in the injected fluid.

The laboratory, located in

Newark City Hospital, opened in March 1895 for the production and preparation of diphtheria antitoxin. The stabled horses, under veterinary supervision, were injected with escalating doses of diphtheria toxin over twelve weeks and were later bled from the jugular vein. The serum, prepared under sterile conditions, was tested for antitoxin

levels, bottled, and distributed free to physicians treating Newark cases. The resident bacteriologist, Dr. R.N. Connolly, reported that "the first antitoxin was ready for me on June 20, 1895." Nine hundred vials were produced in 1895, 567 of which were used in Newark and 94 vials were "sold to persons living outside of the city limits"39

By 1899, twenty-one antitoxin distribution and throat culture stations, established by the Newark Board of Health, were operating in the city. Between 1895 and 1899, the use of antitoxin reduced diphtheria death rates in Newark by ten percent. The health officer remarked that " 286 lives were spared to the community which would have been lost under the old [pre-antitoxin] system. $" 40$

\footnotetext{
${ }^{39}$ R.N. Connolly to the Board of Health, Twentieth Annual Report of the Board of Health of the State of New Jersey (1896): 96-97.

${ }^{40}$ Annual Report of the Department of Public Health, City of Newark (1899): 9, 45.
} 


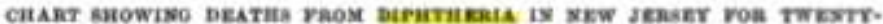
Two reaks, 1679-1900.

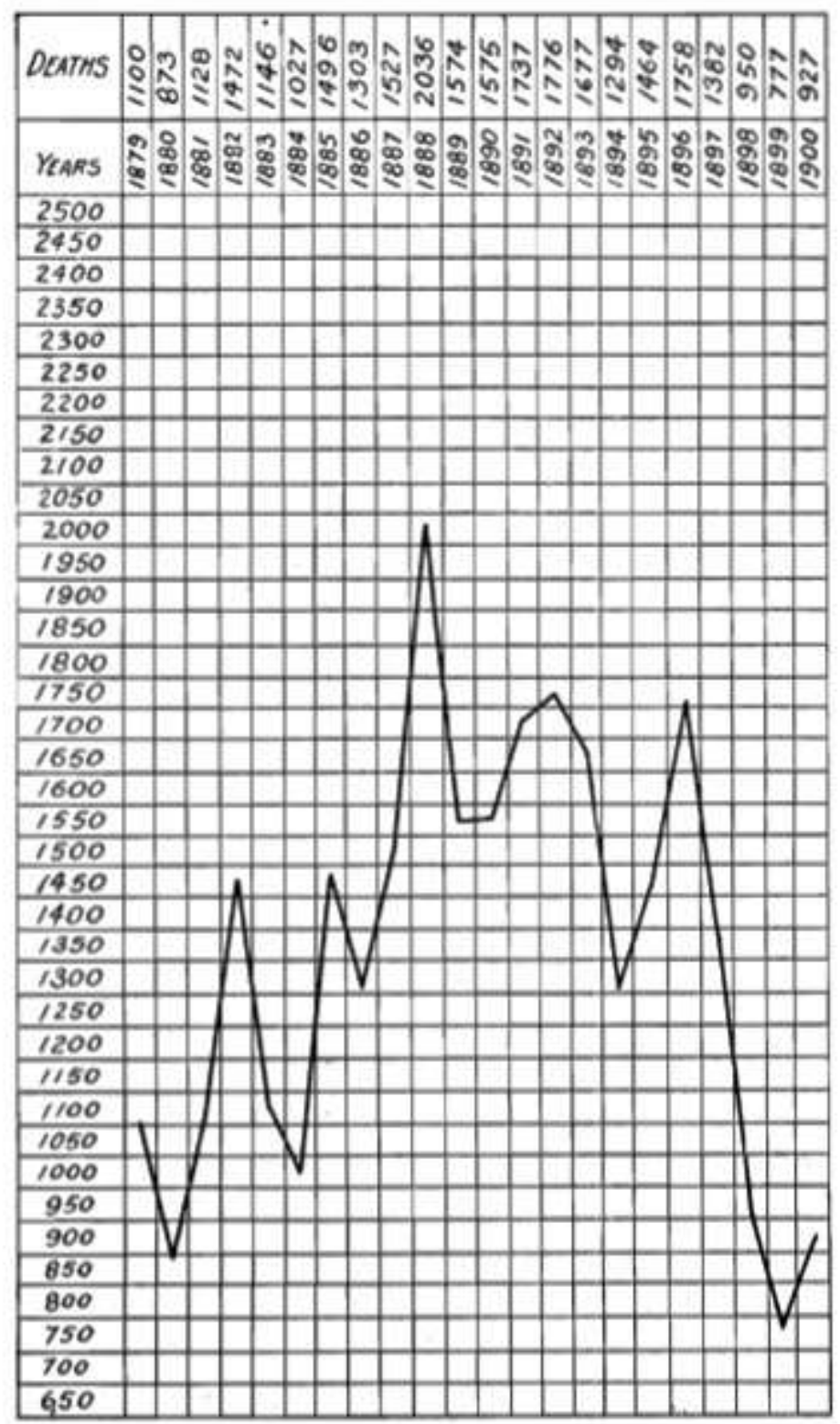

Graph showing the reduction in the number of deaths from diphtheria by about 50 percent within five years of the introduction of diphtheria antitoxin (1895). Annual Report of the Department of Health of the State of New Jersey (1900): 19. 


\section{Early Use of Antitoxin Statewide}

Well-informed New Jersey physicians who kept up to date with the national medical literature, and, in some cases, enjoyed the benefits of proximity to the dynamic medical centers in Philadelphia and New York, transmitted new concepts and practices to their less cosmopolitan colleagues through their county medical society meetings, the New Jersey Medical Reporter (1847), Transactions of the Medical Society of New Jersey (1859), and the Journal of the Medical Society of New Jersey (1904).

Individual practitioners approached antitoxin cautiously, influenced by their own anecdotal experience. In 1895, Dr. John Stevenson of Haddonfield, in his role as custodian of the local board of health, supplied a bottle of antitoxin from New York's private Pasteur Institute to a physician attending a child severely ill with laryngeal diphtheria. When the infant brother of the older child (who had recovered) developed diphtheria, Stevenson was consulted and administered antitoxin from the H.K. Mulford Co. in Philadelphia. The baby also recovered, although the mother developed mild diphtheria despite prophylactic antitoxin. Stevenson concluded (with appropriate caution) from his small series of two cases: "The conclusion is inevitable that either antitoxine or nature was the agent of cure." On the basis of failure of antitoxin to fully protect the mother, he concluded, at least in his single case: "As a preventive of diphtheria, antitoxine was not a success." $" 41$

\section{Bacteriological Laboratory for New Jersey}

In March 1896, the New Jersey State Board of Health opened a bacteriological laboratory to serve physicians and their patients. The emphasis was on diagnosis of diphtheria and tuberculosis, the latter a major cause of adult mortality. Cultures for diphtheria, with results

\footnotetext{
${ }^{41}$ John R. Stevenson, “Antitoxine,” Transactions of the Medical Society of New Jersey (1896): 1895, 234-35; quotations, 235.
} 
available within a day, were a critical guide to antitoxin therapy and to ending quarantine when "the patient ceases to be dangerous to others." ${ }^{42}$ When the state legislature refused to back the project, "public-spirited citizens" funded the laboratory on land owned by the College of New Jersey at Princeton. ${ }^{43}$

Once throat cultures for diphtheria became routine, physicians became aware of the role of the asymptomatic carrier in spreading the disease. In 1910, the director of the State Laboratory of Hygiene, in his report to the Board of Health, cited recent evidence that contact with an asymptomatic carrier was responsible for a large number of diphtheria cases. Carriers were known to harbor the diphtheria bacillus in their throats and noses for months and perhaps years. ${ }^{44}$ The carrier state would remain untreatable until antibiotics became available in the mid-twentieth century.

\section{Embracing — with Caution-a New Kind of Therapy}

Physicians who found early success with antitoxin brought an emotional element to their case reports. In 1896, recoveries in two severe cases led a pair of New Brunswick physicians to conclude, "These two recoveries, in the light of many years' experience with cases of this kind, seems little short of marvelous....We can easily recall many that have proved fatal during the time included by these reports [i.e. since antitoxin was available], which were not treated by antitoxin."45

\footnotetext{
${ }^{42}$ D.M. Ravenel, "Bacteriological Laboratory at Princeton," Transactions of the Medical Society of New Jersey (1896): 183-89; quotations, 183-84.

${ }^{43}$ Henry Mitchell, "Secretary's Report," Nineteenth Annual Report of the Board of Health of the State of New Jersey (1895): 4-5.

${ }^{44}$ R.B. Fitz-Randolph, "Report on the State Laboratory of Hygiene," Thirty-Fourth Annual Report of the Board of Health of the State of New Jersey (1910): 178.

${ }^{45}$ N. Williamson and A.L. Smith, "Cases of Diphtheria Treated by Antitoxin," Transactions of the Medical Society of New Jersey (1896): 429-31; quotation, 431.
} 
The introduction of antitoxin, initially obtained from New York and Philadelphia, generated immediate interest in county medical societies. Dr. Alexander McAllister of Camden was the first to use antitoxin in Camden County. Beginning in January 1895, McAllister treated nineteen diphtheria cases at the West Jersey Orphanage for Colored Children in Camden. Eighteen cases — the nineteenth died before antitoxin could be administered — were injected with antitoxin with rapid clinical improvement, although some had transient paralysis due to circulating diphtheria toxin. Among his private patients, five recovered and two died, one of whom succumbed to what was then referred to as paralysis of the heart, a well-recognized late complication caused by circulating diphtheria toxin. A colleague, Dr. Alexander Marcy of Riverton, who had not personally administered antitoxin to date, expressed "a growing faith in it from what I hear from others, and think it should be thoroughly tested."46

In 1896 and again in 1897, McAllister capably reviewed the history of antitoxin research and development. At this early stage, sera from different laboratories were not standardized. Preservatives such as carbolic acid proved toxic and may have been responsible for sudden deaths following injection, although the possibility of a fatal reaction to horse serum was not considered at the time.

McAllister cited "unfortunate prejudice and professional jealousy of some physicians towards another [presumably himself], who has introduced into a community or locality, a new method of treatment."47 But support was growing. By the date of this report, he had treated forty-

\footnotetext{
${ }^{46}$ Daniel Strock, "Reports of District Societies: Camden County," Transactions of the Medical Society of New Jersey (1895): 225-27; quotation, 227.

${ }^{47}$ Alexander McAllister, "Is the Therapy of Antitoxin Serum, Nuclein Solution and Thyroid Extracts So Fully Established as to Receive the Endorsement of the Profession?" Transactions of the Medical Society of New Jersey (1896): 205-223; quotation, 210.
} 
five cases, administering the serum in most cases within forty-eight hours of diagnosis. At this early date, he used serum from New York and Philadelphia. ${ }^{48}$

He urged his colleagues to embrace antitoxin in the treatment of diphtheria: "Though confronted from the first by the opposition, and materially retarded by the unbridled enthusiasm of some of its advocates, diphtheria antitoxin has, within the brief period of three years, proven itself to be specific [remedy] in the full sense of that term." ${ }^{49}$ After thoroughly reviewing the literature, McAllister reflected that should he be unable to obtain antitoxin when called to a case, "I would have the greatest fears for the safety of my patient; for then I would have to contemplate what was before the sufferer - the days and nights of ceaseless vigil and work, and then the result always doubtful.",50

If some New Jersey physicians were initially skeptical they were not without a measure of justification. Many practitioners were unfamiliar with new explanations of disease grounded in European laboratory science, tending to trust local medical wisdom and personal experience. This new treatment was based not only on the rapidly evolving germ theory of disease, but also on the recent introduction of antitoxin, a mysterious invisible chemical induced by the diphtheria bacterium. Furthermore, in their own experience, other therapies promoted with enthusiasm had proven useless. Rare case reports of sudden death following antitoxin injection also gave them pause.

But with a decade of antitoxin experience, confidence in the treatment grew. In 1906, Dr. J.H. Markley of Camden, gratified by his success with antitoxin, was openly critical of skeptics: "Yet notwithstanding the almost universally favorable reports there are, strange to say, physicians

\footnotetext{
${ }^{48}$ Ibid., 210-211.

49 Alexander McAllister, "The Present Status of the Serum Treatment of Diphtheria," Transactions of the Medical Society of New Jersey (1897), 127-33; quotation, 127.

${ }^{50}$ McAllister, "Is the Therapy of Antitoxin Serum," 212.
} 
who refuse to use it, just as there are physicians who argue that [smallpox] vaccination is...useless. And I hold that the physician who does not use antitoxin in a case of diphtheria, is guilty of ignorant, if not criminal neglect." 51

\section{"Regulars" and Sectarians}

Tension between the "regulars"-members of the Medical Society of New Jersey who were graduates of mainstream medical colleges_and sectarian "irregulars" — mainly homeopathic and eclectic practitioners, as well as faith healers, herbalists, and hydropaths - was an ongoing feature of the late nineteenth and early twentieth-century professional landscape. In 1876, Dr. Ellis P. Townsend of Beverly (Burlington County) observed: "I have seen no cases of diphtheria, or anything resembling it, although our homeopathic men report a great number of cases, with miraculous cures." 52

When increasingly effective pharmaceuticals such as diphtheria antitoxin were developed and adopted, the regular medical profession could move beyond bloodletting and what was commonly referred to as "puking and purging," to begin to offer truly lifesaving treatment. Dr. John Stevenson of Haddonfield described an "insidious and malignant" winter epidemic in 1898. He observed that the "regular" physicians who used antitoxin reported no deaths, while the

\footnotetext{
${ }^{51}$ Paul J.H. Markley, "Some Notes and Observations in Practical Therapeutics," Journal of the Medical Society of New Jersey 2 (1905-1906): 10-18; quotation, 12. Sociologist Gretchen Condran pointed out that deaths from diphtheria appeared to be in decline prior to the introduction of antitoxin, complicating the contemporary analysis of the efficacy of antitoxin therapy. She concluded that antitoxin "apparently accelerated a decline [in diphtheria cases and deaths] that was occurring anyway and for reasons unknown." She suggested that "embracing the antitoxin as a cure was not necessarily wrong, but it was quite likely premature." Gretchen A. Condran, "The Elusive Role of Scientific Medicine in Mortality Decline: Diphtheria in Nineteenth- and Early Twentieth-Century Philadelphia," Journal of the History of Medicine and Allied Sciences 63 (2008): 484-521; quotation, 521. However, leading American pediatrician Abraham Jacobi, in a discussion of reports by over 400 American and Canadian physicians surveyed by the American Pediatric Society in 1897, observed that the use of antitoxin markedly reduced the need for tracheostomy by over 50 percent in cases of laryngeal edema and overall mortality was reduced from about 73 percent to 28 percent. Abraham Jacobi, "Diphtheria: Its Symptomatology and Treatment," in Collectanea Jacobi, ed. William J. Robinson (New York: Critic Guide, 1909), 1:121.

52 Ellis P. Townsend, "Communication by Dr. Townsend," Transactions of the Medical Society of New Jersey (1876): 182.
} 
homeopaths lost a number of children. ${ }^{53}$

Dr. Joseph Craven of the Jersey City Board of Health recounted a successful power struggle with a "disciple of Mother Eddy" (Mary Baker Eddy, founder of the Christian Science movement) who stood between him and a child requiring antitoxin. Because of a delay in calling a physician, the disease had spread to the father and four siblings, who might have been protected by antitoxin. Craven proceeded to inject antitoxin, threatened to remove the child to a contagious disease hospital, and "quarantine the house with you [i.e., the religious healer] in it."

\section{Contagious Disease Hospitals}

In the pre-antibiotic era, most general hospitals did not accept contagious cases. Adults and children with communicable disease who could not be treated or properly quarantined at home were sent to large city or county contagious disease hospitals. The Philadelphia Municipal Hospital for Contagious Diseases was founded in 1866 and the Willard Parker Hospital in New York City opened in 1885 at a site along the East River.

After the turn of the century, many New Jersey children with diphtheria were treated at the Essex County Hospital for Contagious Diseases in Belleville and Camden’s Municipal Hospital for Contagious Diseases, where "the wards would be filled with scarlet fever, measles, diphtheria, chicken pox or mumps, at the epidemic season for each disease." ${ }^{\circ 5}$ In 1922, The Essex County facility, admitted 113 diphtheria cases over six months with nine deaths. ${ }^{56}$

\footnotetext{
53 John C. Doren, "Reports of District Societies: Camden County," Transactions of the Medical Society of New Jersey (1898): 392-407; quotation 396.

${ }^{54}$ Joseph Craven, "Diphtheria in Jersey City and Christian Scientists," Journal of the Medical Society of New Jersey 7 (1910-11): 271.

${ }^{55}$ Camden County Medical Society, "New Jersey Municipal Hospital For Contagious Diseases for the City of Camden," http://www.dvrbs.com/camden/CamdenNJ-MunicipalHospital.htm (accessed March 10, 2020).

56 "Fifteenth Annual Report of the Essex County Hospital for Contagious Disease at Belleville, County of Essex, State of New Jersey, for the Year Ending December 31, 1922," Proceedings and Reports of the Board of Chosen Freeholders of the County of Essex, New Jersey, 1922 (Nuekin Press, Newark, 1922), 723.
} 


\section{The Schick Test and Toxin-Antitoxin Immunization}

Passive immunization with antitoxin early in the disease did much to lower the death rate and prevent transmission to close contacts. In 1905, a decade after the introduction of antitoxin, 676 New Jersey children under age sixteen died of diphtheria. Of these, 392 were between one and five years old ${ }^{57}$ Antitoxin was something_-but it was not everything.

Two threads - one diagnostic and one therapeutic — came together in the years before World War I. Shortly after the turn of the century, Emil von Behring in Germany showed that injection of a carefully balanced mixture of toxin (to stimulate production of anti-diphtheria antibodies) and antitoxin (to protect the experimental animal from the dangerous effects of toxin) could provide long-term active immunity. By 1913, the toxin-antitoxin mixture (TAT) was shown to be effective and safe in humans. ${ }^{58}$

In 1913, Béla Schick, a Hungarian-born pediatrician working at the University of Vienna, developed a skin test to detect circulating antibodies to diphtheria and hence determine if a child was immune. While full-blown cases of classic diphtheria were understood to confer lifelong immunity, mild or even asymptomatic cases could also confer immunity. The Schick test required an injection of a minute dose of toxin into the superficial layer of forearm skin. In the non-immune child, the toxin acted as an irritant, causing a red, raised area at the site of injection, an indication that the toxin was not neutralized by circulating antibodies. Such children, therefore, had no immunity to diphtheria (positive test). In immune children with circulating antidiphtheria

\footnotetext{
57 "Deaths in New Jersey from Diphtheria, with Ages of Decedents, for Year Ending December 31, 1905," Annual Report of the Board of Health of the State of New Jersey, (1906): 35.

${ }^{58}$ Kornelia Grundmann, The Nobel Prize: Emil von Behring, https://www.nobelprize.org/prizes/medicine/1901/behring/article/ (accessed March 2020).
} 
antibodies, the test toxin was neutralized, leaving only a slight brownish pigmentation at the injection site (negative test). ${ }^{59}$

Positive Schick test reactors were candidates for toxin-antitoxin administration to stimulate the production of antibodies and long-term (possibly lifelong) immunity. Schick negative children did not require immunization.

In 1913, the New York City Board of Health, under the direction of bacteriologist and laboratory director William H. Park and assistant director Abraham Zingher, began immunization trials at the Willard Parker Hospital (for communicable diseases) and children's custodial institutions. Follow-up Schick tests confirmed immunity. By 1921, Park had extended the immunization program to tens of thousands of New York schoolchildren. ${ }^{60}$

\section{Statewide Testing and Immunization in New Jersey}

In 1922, Dr. Joseph Shapiro read a paper before the Hudson County Medical Society on “The Schick Test as a Public Health Measure.” After summarizing Park's success with Schick testing and TAT immunization in New York, Shapiro reviewed details of Schick testing as a guide for other New Jersey physicians. In addition to immunizing susceptible children, he advised that immunization should be employed routinely in "contagious disease hospitals, insane asylums, private schools, etc." Immunity appeared lasting and "in the opinion of those most actively engaged in the work, it is probably life-long." Shapiro reported the results of 1600 Schick tests in school children in Union Hill (now Union City). Six hundred of the children were susceptible and were in the process of being immunized. The problem remained of reaching pre-school children in whom mortality rates exceeded 80 percent. Shapiro urged private physicians, school health

\footnotetext{
${ }^{59}$ Schick later immigrated to New York in 1923 to take up the post of chief of pediatrics at Mount Sinai Hospital. He supported diphtheria testing and immunization campaigns in New York. Antoni Gronowicz, Béla Schick and the World of Children (New York: Abelard-Schuman, 1954), 123-31.

${ }^{60}$ Hammonds, Childhood's Deadly Scourge, 178-82.
} 
officers, and public health officials to become "aggressive agents in making this work [testing and immunization] popular."61

Between 1910 and 1920, New Jersey diphtheria deaths per 100,000 population fell from 28.6 to 17.9 . However, 1921 was worrisome with a small spike in the death rate to 18.3 per 100,000 , despite efforts by state and local health officials to contain the disease by means of isolation, quarantine, disinfection, and antitoxin. The proposed solution was a more general use of toxin-antitoxin immunization guided by the "safe and reliable test [the Schick test] to identify those who are susceptible... The morbidity and mortality from diphtheria should, in the course of a few years, show a marked decline." 62

Always worrisome was the potential for quickly spreading outbreaks within custodial and residential institutions. The New Jersey State Department of Health acted quickly to limit transmission. In 1917, small outbreaks at the Training School for Boys (Vineland), New Jersey State School for the Deaf (Trenton), and New Jersey State Institution for the Feeble Minded (Trenton) led to facility-wide Schick testing in cooperation with local health authorities, with administration of toxin-antitoxin to susceptible residents and staff. ${ }^{63}$

\section{Refining Immunization: Toxoid}

In 1923, Gaston Ramon in Paris and Alexander Glenny in London inactivated diphtheria toxin by treating it with formalin. The inactivated toxin-dubbed "toxoid" — retained the power to provide long-term immunity, while avoiding the side effects of TAT. In 1926, Glenny substituted aluminum salts for formalin, producing an even safer and more effective vaccine. ${ }^{64}$

\footnotetext{
${ }^{61}$ Joseph Shapiro, “The Schick Test as a Public Health Measure,” Journal of the Medical Society of New Jersey 19 (1922): 164-67; quotations, 165, 167.

62 "Reported Cases and Deaths from Diphtheria in New Jersey from 1909 to 1921," Annual Report of the Department of Health of the State of New Jersey (1922): 44.

63 "Communicable Diseases at State Institutions," Annual Report of the Department of Health of the State of New Jersey (1917): 51-53.

${ }^{64}$ College of Physicians of Philadelphia, History of Vaccines Timeline,
} 
By 1928, both TAT and toxoid were being supplied to New Jersey municipalities by the Department of Health. Over 125,000 New Jersey children were immunized at public clinics in 1928. Local and state health officials ran education programs and clinic demonstrations, aided by the New Jersey Committee for the Prevention of Diphtheria. ${ }^{65}$

In 1934, the state legislature enacted a law requiring the Department of Health to distribute diphtheria toxoid (and smallpox vaccine) at no cost. By the end of 1935, there were fifty-eight distribution stations in the state, where local physicians could obtain the toxoid and reporting forms for use in their private office practices. Close to fourteen hundred private physicians reported administration of diphtheria toxoid obtained through the program. ${ }^{66}$

\section{The Long Road to Zero}

In 1939, there were 453 diphtheria cases (a quarter in preschool children) with 25 deaths. While far short of the carnage of previous decades, these cases and deaths were seen as preventable by public health officials. What was needed were "continuous and determined efforts to have parents seek for their young children the protection afforded against this disease by toxoid." ${ }^{67}$ In contrast to the current parental anti-vaccination sentiment driving dangerous refusals to immunize children, the problem in 1939 was perceived as a failure of physicians and public health officials to reach and inform the families of pre-school-age children. And indeed, the passing decades brought remarkable decreases in cases and deaths. The statewide statistics spoke for themselves (cases/deaths): 1920: 6931/566; 1930: 4162/331; 1940: 330/23; 1950: 50/0; 1960: 1/0.68

\footnotetext{
https://www.historyofvaccines.org/timeline/all (accessed March 10, 2020).

65 "Report of the Director," Annual Report of the Board of Health of the State of New Jersey (1929): 9.

66 "Report of the Director of Health," Annual Report of the Department of Health of the State of New Jersey (1935):

11; "Free Biologicals," Annual Report of the Board of Health of the State of New Jersey (1935): 36.

${ }^{67}$ William H. MacDonald, "Report of the Bureau of Local Health Administration," Annual Report of the Board of Health of the State of New Jersey (1940): 32.

${ }^{68}$ Annual Report of the Board of Health of the State of New Jersey (year/page) (1921): 43; (1931): 29; (1941): 45-

46; (1951):182); (1962): 164.
} 


\section{The "D" in DPT}

Today, the only contact New Jerseyans — and their physicians — have with diphtheria is the “D” in DPT - the triple vaccine introduced in 1948 against diphtheria, pertussis (whooping cough), and tetanus. The World Health Organization reported only three cases of diphtheria in the United States since $2000 .{ }^{69}$ But worldwide, reported cases numbered some 15,000 in $2018 .{ }^{70}$ With the collapse of the healthcare system in Venezuela, which was free of diphtheria from 1990 to 2015, there were close to 800 reported cases in both 2017 and $2018 .^{71}$ While such a scenario seems unimaginable in the United States, vigilance - through strong governmental and parental support of regular immunizations and boosters sufficient to maintain herd immunity - will continue to protect New Jersey children from "That Terrible Disease Vulgarly Called The Throat-Distemper."

\section{Conclusion}

Diphtheria played an important role in shaping scientific concepts of infectious diseases and their treatment and prevention in the nineteenth and early twentieth century ${ }^{72}$ The pathbreaking research generated in laboratories in Europe, exported to metropolitan health departments in cities like New York, transmitted to New Jersey's state and city health departments, articulated by intellectually engaged local physicians through their county medical societies, and brought to the bedsides of children by ordinary practitioners, all served to demonstrate to New Jersey parents that New Jersey doctors, armed with this wondrous new science, were learning how

\footnotetext{
${ }^{69}$ WHO Vaccine-preventable Diseases: Monitoring System. 2019 Global Summary (United States of America), https://apps.who.int/immunization monitoring/globalsummary/countries?countrycriteria\%5Bcountry\%5D\%5B $\% 5 \mathrm{D}$ =USA (accessed March 23, 2020).

${ }^{70} \mathrm{WHO}$, Diphtheria Reported Cases,

http://apps.who.int/immunization_monitoring/globalsummary/timeseries/tsincidencediphtheria.html (accessed March 23, 2020).

${ }^{71}$ WHO Vaccine-preventable Diseases: Monitoring System. 2019 Global Summary (Venezuela), https://apps.who.int/immunization_monitoring/globalsummary/countries?countrycriteria $\% 5 \mathrm{Bcountry} \% 5 \mathrm{D} \% 5 \mathrm{~B} \% 5 \mathrm{D}$ =VEN (accessed March 23, 2020). The number of unreported cases in Venezuela may be considerable.

${ }^{72}$ Peter C. English, "Diphtheria and Theories of Infectious Disease: Centennial Appreciation of the Critical Role of Diphtheria in the History of Medicine," Pediatrics 76 (1985): 1-9.
} 
to save children.

\section{Coda}

New Jersey physician, short story writer, and poet William Carlos Williams graduated from the University of Pennsylvania School of Medicine in 1906 and opened his general and pediatric medical practice in Rutherford in 1910. Almost certainly, he encountered cases of diphtheria during training and in his private practice. His short story, "The Use of Force," appears to be set in the 1920s or 1930s and begins with an urgent house call to Matilda, a defiant little girl sick with fever. The doctor suspects diphtheria and, though unstated, must make the diagnosis to prompt urgent administration of potentially lifesaving antitoxin. The doctor grows increasingly furious at "the damned little brat," who clenches her jaw and "fights valiantly to keep her secret." He ultimately resorts to brute force to pry Matilda's jaw open - and finds her tonsils covered with pseudomembrane, confirming the diagnosis of diphtheria. Williams leaves the reader to contemplate the doctor's shame and shock at his furious and "unreasoning" assault on a sick child. $^{73}$

Sandra W. Moss graduated from Rutgers Medical School (1969) and the Mount Sinai School of Medicine (1971) and practiced internal medicine in New Brunswick and Edison. She earned a master's degree in the History of Technology, the Environment, and Medicine from the Rutgers University (Newark)-New Jersey Institute of Technology affiliated program in 2005. She is past president of the Medical History Society of New Jersey and the author of four books and many articles dealing with the history of medicine, with an emphasis on the history of medicine in New Jersey.

\footnotetext{
73 “The Use of Force," https://www.classicshorts.com/stories/force.html (accessed March 20, 2020). The story first appeared in the collection Life Along the Passaic River, published in 1938.
} 